\title{
OBRIGATORIEDADE ESCOLAR E INVESTIMENTO NA EDUCAÇÃO PÚBLICA: UMA PERSPECTIVA HISTÓRICA (SÃO PAULO, 1874-1908)
}

\author{
Wiara Rosa Alcantara ${ }^{1}$
}

\section{RESUMO}

O objetivo do artigo é discutir como São Paulo foi se organizando administrativa e financeiramente para assumir a responsabilidade pela criação e expansão da escola pública, moderna, obrigatória e de massas, a partir da primeira lei paulista de obrigatoriedade escolar, a Lei n. 9 de 22 de março de 1874. A delimitação temporal final é 1908, ano em que foi regulamentado o funcionamento do almoxarifado da Secretaria de Estado dos Negócios do Interior, com atribuição específica de adquirir, arrecadar e distribuir todo o material de ensino às escolas públicas. O procedimento metodológico consiste em tomar a materialidade da escola como fio condutor indagando como o Estado foi, paulatinamente, atuando na abertura de escolas e fornecimento dos materiais e móveis necessários ao funcionamento das mesmas. Destaca-se que, de um lado, a administração pública e escolar foi se tornando mais complexa e formal na prestação do serviço educacional. De outro, evidencia-se que as demandas emanadas do interior das instituições de ensino também impulsionaram e exigiram uma maior organização administrativa, como a criação de órgãos e contratação de servidores para cuidar da

${ }^{1}$ Universidade Federal de São Paulo (Unifesp), São Paulo/SP, Brasil. 
compra e distribuição de material e mobiliário para as escolas espalhadas pelo território paulista. Examinando fontes como correspondências e ofícios de solicitação de compra de objetos escolares, livros de registro de material da Instrução Pública, orçamentos, dentre outras, é possível perceber como esta escola moderna exigiu maior investimento do Estado para dar conta da obrigatoriedade escolar.

Palavras-chave: cultura material escolar, história administrativa, história econômica, obrigatoriedade escolar, investimento na educação.

\section{ESCUELA OBLIGATORIA E INVERSIÓN EN EDUCACIÓN PÚBLICA: UNA PERSPECTIVA HISTÓRICA (SÃO PAULO, 1874-1908)}

\section{RESUMEN}

El propósito de este documento es discutir cómo São Paulo se organizó administrativa y financieramente para asumir la responsabilidad de la creación y expansión de la escuela pública, moderno, obligatorio y masivo, de la primera ley de São Paulo de la escuela obligatoria, la ley $\mathrm{n}^{\circ}$ 9 de marzo de 1874. La delimitación temporal final es 1908, el año en que se reguló el funcionamiento del almacén del Secretario de Estado de Asuntos Interiores, con la atribución específica de adquirir, recolectar y distribuir todo el material didáctico a las escuelas públicas. El procedimiento metodológico consiste en tomar la materialidad de la escuela como un hilo conductor preguntando cómo el estado estaba actuando gradualmente en la apertura de las escuelas y el suministro de materiales y muebles necesarios para su funcionamiento. Cabe destacar que, por un lado, la administración pública y escolar se estaba volviendo más compleja y formal en la prestación de servicios educativos. Por otro lado, es evidente que las demandas que emanan del interior de las instituciones educativas también impulsaron y exigieron una mayor organización administrativa, como la creación de órganos y la contratación de servidores para encargarse de la compra y distribución de material y mobiliario para las escuelas dispersas en todo el territorio paulista. Examinando fuentes como correspondencia y cartas de compra de objetos escolares, libros de registro de material de Instrucción Pública, presupuestos, entre otros, es posible ver cómo esta escuela moderna requirió una mayor inversión del Estado para hacer frente a la escuela obligatoria.

Palabras clave: cultura material escolar, historia administrativa, historia económica, escuela obligatoria, inversión en educación.

\section{COMPULSORY SCHOOL AND INVESTMENT IN PUBLIC EDUCATION: A HISTORICAL PERSPECTIVE (SÃO \\ PAULO, 1874-1908).}

\section{ABSTRACT}

This article aims at discussing how São Paulo has been organized administratively and financially to be responsible for the creation and the expansion of the public, modern, mandatory and mass school, from the first Paulista law of the mandatory school, the n. 9 Law, 
March 22nd, 1874. The final temporal delimitation is 1908, the year when it was regulated the operation of the warehouse of the Countryside Business State Secretary, with the specific role of acquiring, collecting, and distributing the whole teaching material to the public schools. The methodological procedure consists on taking the school materiality as a conducting wire asking how the State was, gradually, acting on the school openings and on the supply of the necessary materials and furniture to their functioning. It is highlighted, on the one hand, that the public and school administration has been more complex and formal on the school service delivery. On the other hand, it is evident that the internal demands of the teaching institutions also boosted and required a bigger administrative organization, such as the creation of some organizations and the hiring of workers to take care of the buying and the distribution of the material and the furniture to the schools spread though the Paulista territory. Taking into account some sources, such as the correspondences and crafts solicitation of buying of the school objects, the register books of materials of the Public Instruction, the budgets, among others, it is possible to recognize how this modern school demanded a bigger investment of the State to supply the school mandatory.

Keywords: school material culture, administrative history, economic history, school mandatory, investment on education.

\section{ÉCOLE OBLIGATOIRE ET INVESTISSEMENT DANS L'ÉDUCATION PUBLIQUE: PERSPECTIVE HISTORIQUE (SÃO PAULO, 1874-1908)}

\section{RÉSUMÉ}

Le but de l'article est de discuter comment São Paulo s'organisait sur le plan administratif et financier pour prendre en charge la création et l'expansion de l'école publique, moderne, obligatoire et de masse, de la première loi de l'école obligatoire à São Paulo, la loi no 9 mars 1874. La délimitation temporelle finale est 1908, année de réglementation du fonctionnement de l'entrepôt du Secrétaire d'État aux Affaires Intérieures, qui attribue spécifiquement l'acquisition, la collecte et la distribution de tout le matériel pédagogique aux écoles publiques. La procédure méthodologique consiste à prendre la matérialité de l'école comme un fil conducteur demandant comment l'État a progressivement agi lors de l'ouverture d'écoles et de la fourniture du matériel et du mobilier nécessaires à leur fonctionnement. Il est à noter que, d'une part, l'administration publique et l'école devenaient de plus en plus complexes et formelles dans la fourniture de services éducatifs. D'autre part, il est évident que les demandes émanant de l'intérieur des établissements d'enseignement ont également stimulé et exigé une organisation administrative plus grande, telle que la création d'organes et le recrutement de serveurs pour prendre en charge l'achat et la distribution de matériel et de mobilier pour les écoles dispersées sur le territoire de Sao Paulo. En examinant des sources telles que la correspondance et les lettres d'achat d'objets scolaires, les registres de matériel d'instruction publique, les budgets, entre autres, il est possible de voir comment cette école moderne a nécessité un investissement plus important de la part de l'État pour faire face à la scolarité obligatoire.

Mots-clés: culture matériel scolaire, histoire administrative, histoire économique, école obligatoire, investissement dans l'éducation. 


\section{INTRODUÇÃO}

O Plano Nacional de Educação (2014-2024) estabelece entre suas metas a universalização, até 2016, da educação infantil na pré-escola para as crianças de 4 (quatro) a 5 (cinco) anos de idade; a universalização do ensino fundamental de 9 (nove) anos para toda a população de 6 (seis) a 14 (quatorze) anos; e, a universalização, até 2016, do atendimento escolar para toda a população de 15 (quinze) a 17 (dezessete) anos. Tais metas expressam desafios históricos da educação pública brasileira.

Embora não se limite aos aspectos econômicos, as referidas metas estão intrinsecamente relacionadas a questões como fonte de recursos, ao financiamento e investimento na educação pública. Tomando o caso particular de São Paulo, empreendo, sob uma perspectiva histórica, reflexão acerca dos desafios quanto ao investimento na instrução pública, na criação de escolas e de suas condições físicas de funcionamento, a partir da primeira lei de obrigatoriedade do ensino primário, a Lei n. 9 de 22 de março de 1874.

Abordar o problema da obrigatoriedade do ensino e do investimento na educação pública, sob uma perspectiva histórica, lança luz na compreensão dos desafios e das ações a serem empreendidas para ampliação da escolaridade e das oportunidades educacionais. Para tanto, é fértil o estudo da institucionalização da escola pública primária, da organização da administração pública e escolar e do investimento do poder público na educação nas últimas décadas do século XIX, quando o Estado passa a assumir, mais efetivamente, a responsabilidade pela prestação de serviços públicos. Estas questões, embora amplas, serão abordadas de forma inicial e interligadas neste estudo. Isso porque a expansão da escola moderna de massa e obrigatória exigiu uma melhor estruturação da administração pública e um maior investimento do governo para efetivar a escolarização obrigatória.

No caso da Província de São Paulo, a obrigatoriedade do ensino primário é estabelecida pela Lei n. 9 de 22 de março de 1874, que define em seu 
$\operatorname{artigo} 1^{\mathrm{O}}$ :

O ensino primário é obrigatório para todos os menores de 7 a 14 annos do sexo masculino, e 7 a 11 do sexo feminino, que residirem dentro de Cidade ou Villa em que houver escola publica ou particular subsidiada, não tendo elles impossibilidade physica ou moral.

Após a lei de obrigatoriedade, a lei n. 55 de 30 de março de 1876 "mandou que fossem construídos prédios apropriados para as escolas publicas"2. Aquilo que Candeias (2004, p. 43) expõe sobre o ensino em Portugal, é elucidativo, neste ponto, para o caso paulista. Segundo ele, é somente "a partir de meados do século XIX [que a escola] se organiza em rede e se articula com outras formas de educação, sob o comando político, pedagógico e administrativo do Estado".

Nas palavras de Diana Vidal (2013, p. 14), "não é possível supor, entretanto, que, uma vez promulgada, a obrigatoriedade do ensino foi instaurada nas respectivas Províncias". Isso devido às

[...] condições materiais da administração provincial, como precariedade orçamentária, ausência de professores habilitados, dispersão territorial, dentre outras razões citadas como limitantes à plena aplicação da obrigatoriedade escolar ou como justificativas do descompromisso dos governos provinciais [...] (VIDAL, 2013, p. 15).

Tornar o ensino obrigatório exigiria um maior investimento do Estado na instrução pública, a começar pela criação de escolas e pelo suprimento material das mesmas. Neste trabalho, tomo a materialidade da escola como um fio condutor para pensar desafios na concretização da obrigatoriedade do

\footnotetext{
2 Relatório da Instrucão Pública da Província de São Paulo de 1879, apresentado ao Presidente da Província pelo Inspetor Geral da Instrucão Pública, Francisco Aurélio de Souza Carvalho, anexo ao Relatório apresentado à Assembléa Legislativa Provincial de S. Paulo pelo presidente da provincia, Laurindo Abelardo de Brito, no dia 5 de fevereiro de 1880. Santos, Typ. a Vapor do Diario de Santos, 1880 , p. 7.
} 
ensino, encabeçada pelo Estado. Primeiro, abordarei a organização de uma estrutura administrativa e burocrática, as questões administrativas; depois, as questões econômicas como elementos fundamentais na criação e expansão da escola pública, obrigatória e de massa, em São Paulo, nas últimas décadas do século XIX.

\section{O DESAFIO DA ORGANIZAÇÃO ADMINISTRATIVO- ESCOLAR: UMA PERSPECTIVA HISTÓRICA}

Em linhas gerais, a administração é a estruturação e organização do Estado, estabelecendo competência de órgãos e agentes, tendo em vista a prestação de serviços públicos. Nas últimas décadas do século XIX, a administração pública e escolar foi se tornando mais complexa. Casemiro dos Reis Filho (1981, p. 19), afirma que "entre 1890 e 1896 realizou-se o mais intenso esforço de racionalização político-administrativo no governo de São Paulo. Como parte desse processo, organizou-se o ensino público paulista”.

Aqui, não interessa expor como estava organizada burocrática e hierarquicamente a administração da instrução pública. Isso já foi feito em outros estudos3. Ainda que de forma inicial, para além da estrutura estabelecida na lei, interessa ver, a partir dos modos de suprimento material da escola, os órgãos da administração e da instrução pública "em funcionamento".

Nesse sentido, o Livro de Moveis e Utensis (Distribuição de 1854 a 1872)4 oferece indícios de como a administração pública paulista foi, paulatinamente, organizando-se para criar as condições físicas de

\footnotetext{
3 O tema da estrutura administrativa da Instrução Pública paulista, na Primeira República, já foi objeto de estudo de João Lourenço Rodrigues (1930); Moacyr Primitivo (1942); Reis Filho (1974); Degani (1973); Nascimento (1980); Tavares (2004); Souto (2005); Paulo (2007); Warde e Parizzolo (2009).

4 Vale mencionar que a busca por esta documentação deveu-se a menção da mesma na dissertação de Valdeniza Barra (2001) sobre a lousa escolar. Arquivo Público do Estado de São Paulo. Livro de Móveis e Utensis (Distribuição de 1854 a 1872). Secretária da Instrução Pública de São Paulo. Ordem 1124.
} 
funcionamento das escolas. Nele, são registradas autorizações às professoras e aos professores para compra dos móveis e material escolar.

O Livro contém, também, o registro do mobiliário de diversas escolas da Província de São Paulo, o valor de cada item e o modo como chegaram aos estabelecimentos de ensino. O Livro servia para "n'elle se lançarem os utensis, e as quantias para a compra dos mesmos, e dos moveis que foram fornecidos aos estabelecimentos d’Instrução Pública desta Província”5.

No verso da primeira página do Livro, datada do ano de 1854, registrase a importância entregue à professora Maria Francisca da Conceição Barbosa ( 51 \$0oo) e ao professor Manuel Dias da Silva (44\$600) para compra de móveis. Essa situação pode ser observada até os anos de 1868 e 1869, mas também há compras que são feitas pelos Inspetores do Distrito, como se nota nas páginas 2 e 3 (verso), 4 (verso), 5 e 5 (verso), 7.

Nesse momento, o investimento, quando existia, parecia obedecer ao critério do "mínimo necessário", isto é, 1 estrado, 1 cadeira e 1 mesa para professor e bancos e bancas para os alunos. A professora ou o professor se responsabilizavam pela compra do material e mobiliário escolar, quando não com o dinheiro da Província, com o seu próprio.

Um conjunto de correspondências de professoras e professores primários, localizado no Arquivo Público do Estado de São Paulo, demonstra como, paulatinamente, a responsabilidade pela estrutura física e pelo suprimento material da escola foi sendo assumida pelo poder público. É denunciando a ausência de tais condições que a professora da "Escola Pública Primária do Primeiro Districto desta Capital”, Amelia de Oliveira Carvalho, em 30 de maio de 1881, escreve ao Inspetor Geral da Instrução Pública, Dr. Francisco Aurelio de Souza Carvalho:

\footnotetext{
5 Arquivo Público do Estado de São Paulo. Ordem 1124 - Livro de Móveis e Utensis. Termo de Abertura.
} 
Professora nomeada para reger aula do primeiro Districto, em 1868 , tive então que lutar com todas as dificuldades, como se tivesse de tomar conta de uma escola recentemente creada; sem alumnas, porque as primeiras acompanharão a minha antecessora para a sua nova cadeira, sem casa e sem moveis, porque esta escola funcionava no pavimento térreo do Thesouro Provincial, e d'ahi mudada por ordem do Governo, e os moveis ahi existentes ficarão em poder da minha antecessora. Foi então que em luta com esses embaraç,os encontrei o auxilio de alguns paes que desejando matricular suas filhas em minha aula, esforçarão-se por achar uma sala onde eu pudesse dar começo aos trabalhos escolasticos. Da mesma sorte encontrei promptidão da parte de V. Sa. em attender ao pedido que fiz de moveis e utensis e assim pude abrir a escola. Entretanto [...] a sala onde funcciona a escola é pequena, escura e com falta de todas as accomodações hygienicas, necessárias para um lugar em que diariamente há uma aglomeração de pessoas. $\mathrm{E}$ a este respeito é com pezar com menciono o facto de sermos obrigadas a tirar do nosso precário ordenado uma quota para o aluguel de um cubículo onde se bem que vexatoriamente possamos exercer o nosso magistério, enquanto que outras Professoras trabalhão em edifícios apropriados e fornecidos pelo Governo ${ }^{6}$.

O ofício da professora denuncia uma situação que se prolongou após a Lei de obrigatoriedade, de 1874. Outra professora, Isabel Maria da Glória Vieira, cuja escola foi criada em 1882, relata:

A minha escola [...] foi creada o ano passado e até hoje ainda não foi provida de moveis e utensis apenas recebi da substituta alguns exemplares e na Repartição da Instrução Pública outros de que existe recebi nessa Repartição, quanto aos moveis e utensis, não só por ser a minha eschola nova, matricula e frequência de alumnas como também para a boa marcha do ensino é necessário que V. Sa. mande fornecer os mesmos, e além disto nada mais tenho a relatar a V. Sa. A Profa. Pública Normalista - Isabel Maria da Glória Vieira7.

Em torno do ano de 1870, ou seja, em anos anteriores à aprovação da

\footnotetext{
${ }^{6}$ Arquivo Público do Estado de São Paulo. Instrução Pública - Relatório das localidades Capital, anos: 1852-1888; Caixa 12; Ordem 4930.

7 Arquivo Público do Estado de São Paulo. Instrução Pública - Relatório das localidades Capital, anos: 1852-1888; Caixa 12; Ordem 4930 - Relatório escolares - 1883; Pasta 23, maço 3 - Papeis fechados 23.
} 
Lei n. 9 de 22 de março de 1874, o material que chegava à escola, conforme o Livro de Moveis e Utensis, já era mais diversificado e os modos de aquisição, mais formais. Isso significa que o incremento material da escola e uma progressiva complexificação burocrática da instrução pública são anteriores à lei de instrução obrigatória e à Proclamação da República. Embora não se possa negar que ambos os acontecimentos tiveram contribuições importantes tanto para equipar materialmente a escola quanto para maior organização da instrução pública.

No ano de 1869, a escola do Bairro das Almas, como outras, recebeu também utensis: Louzas (27), canetas de latão (27), lápis de pedra (27), traslados cortidos (90), garrafas de tinta (6), tinteiro e areeiro (1), Quadros Históricos (8) e Geográficos (6) da Província. No entanto, não constam mais as importâncias entregues diretamente aos professores, professoras e inspetores. A informação a partir daquele ano passa a ser: "N'esta data foram entregues ao respectivo professor, n'esta Secretaria os seguintes Utensis"8. Se o material escolar vai se diversificando, o mobiliário permanece o mesmo, bancos e bancas, mas a forma de adquiri-los torna-se mais complexa.

A partir de 1870, o Inspetor do Tesouro e a Coletoria começam a participar das aquisições dos materiais escolares. Sobre a $1^{\text {a }}$ Cadeira de $1^{\text {as }}$ Letras do sexo feminino de Mogi-Mirim, lê-se: "Nesta data [26 de janeiro de 1870] officiou-se ao Inspetor do Thezouro solicitando-se expedição de ordem ao Collector da cidade supra para pagar a importancia dos móveis e utensílios fornecidos á esta escola [...]”9.

Quando se refere aos materiais, apenas consta que eles foram "entregues ao professor pela Secretaria", ou seja, a Secretaria da Instrução Pública de São Paulo. Também, não há menção de valor monetário dos objetos. Já quando se trata dos móveis, envia-se um ofício ao Inspetor do Tesouro solicitando expedição de ordem ao Coletor da cidade para pagamento dos

\footnotetext{
8 Arquivo Público do Estado de São Paulo. Ordem 1124 - Livro de Móveis e Utensis, p. 88.

9 Idem, p. 75 .
} 
móveis ${ }^{10}$. Em quase todas as escolas da Província, os móveis entregues foram:

- 6 bancos de 10 palmos de comprimentos -------------------27\$00o

- 3 bancas de 10 palmos de comprimentos e 2 1/2 de largura --15\$0oo

- 1 meza de 5 palmos em quadra ---------------------20\$000

- 1 cadeira para o professor -------------------------18\$000

VALOR $=80 \$ 000$

Isso pode indiciar que, enquanto os utensílios já estavam disponíveis na Secretaria, os móveis seriam fabricados de acordo com a demanda. Provavelmente, feitos por um mesmo fabricante na mesma quantidade e mesmo valor para todas as escolas. O pagamento dos móveis era feito pelo Coletor da cidade, depois de autorização dada pelo Inspetor do Tesouro.

Na hierarquia de administração tributária, o Inspetor do Tesouro era o funcionário abaixo do Presidente da Província. Ele deveria dar as ordens para liberação da verba pelo Coletor da cidade. Como uma das Estações Arrecadadoras, a Coletoria era composta por um coletor e um escrivão. "As Coletorias eram as Estações encarregadas da arrecadação da receita comum interna da Província” (TESSITORE, 1995, p. 91).

O Livro de Móveis e Utensis revela, no período: 1) uma organização pouco especializada do governo para resolver as demandas materiais e problemas do ensino; 2) um envolvimento muito direto do Presidente da Província com as mais diversas questões relativas à Instrução Pública. Reis Filho (1981, p. 19) explicita que era uma

administração extremamente simples e quase sem intermediários [...] As dificuldades decorriam da falta de uma linha hierárquica definida, de autoridade, que o patriarcalismo administrativo supria. Em última

${ }^{10}$ Idem, p. 93. 
instância, todos os problemas encontram solução ao nível do chefe supremo do Governo do Estado (REIS FILHO, 1981, p. 19).

Reis Filho (1981) detalha as relações administrativas que afetam a estrutura escolar. No entanto as fontes indiciam que a própria estrutura escolar também vai afetando as relações administrativas já que com a expansão da escola torna-se inviável que todas as decisões quanto à aquisição de mobiliário, material escolar, reforma, criação de escolas, contratação, afastamento, demissão e aposentadoria de professor, de todas as escolas de São Paulo passem diretamente pelo chefe maior do executivo. Ou seja, a dinâmica escolar também exigiu mudanças na estrutura da administração pública para atender às demandas em prol da expansão da escola de massa.

Exemplo disso é o almoxarifado, criado como uma seção da Diretoria Geral da Instrução Pública em 1895 pela Lei n. 374, de 3 de setembro de 1895, em seu artigo $8^{\circ}$. O Diretor Geral da Instrução Pública, Dr. Arthur César Guimarães, solicita ao Secretário do Interior, Alfredo Pujol, a organização do almoxarifado. Em 10 de setembro, Alfredo Pujol informa que "já se providenciou sobre a nomeação de um funcionário em comissão" ${ }^{11}$ para a Repartição da Instrução Pública (Quadro 1).

${ }^{11}$ Fonte: Série Manuscritos. Instrução Pública. Ofícios do Governo ao Inspetor Geral. Anos 1894-1896. Caixa 9 / Ordem - 4992. Ofício n. 364. 
Quadro 1 - Ofício de Alfredo Pujol em 1895.

\section{A SECRETARIA DO ESTADO DOS NEGÓCIOS DO INTERIOR}

São Paulo, 10 de setembro de 1895

$3^{\text {a }}$ secção - n. 364

Ao cidadão Dr. Diretor Geral da Instrução Publica

Respondendo a vosso oficio n. 843, de 3 do corrente, em que pedistes providencias no sentido de ser organizado o almoxarifado dessa Repartição, tenho a declarar-vos que já se providenciou sobre a nomeação de um funcionário em comissão.

Alfredo Pujol

Fonte: Apesp, Série Manuscritos. Instrução Pública. Ofícios do Governo ao Inspetor Geral. Anos 1894-1896. Caixa 9/Ordem - 4992.

Antes da criação do Almoxarifado específico da Instrução Pública, os materiais e mobiliário para as escolas públicas paulista poderiam ser guardados no depósito da Escola Normal da Praça da República, no Almoxarifado da Secretária do Interior e até no Tesouro Provincial. Ou seja, não havia um almoxarifado específico voltado somente às necessidades da escola, da Instrução Pública. $\mathrm{O}$ aumento do número de escolas e as constantes reivindicações de materiais tornaram a situação insustentável.

Assim, se o Decreto n. 144A, de 30 de dezembro de 1892 criou a Secretaria Geral da Instrução Pública com três seções, a Lei n. 374, de 1895 alterou a organização da Secretaria com a criação da $4^{\mathrm{a}}$ seção, "incumbida do almoxarifado da própria Secretaria” (PAULO, 2007, p. 57).

A análise dos elementos formais de um ofício anterior à criação do Almoxarifado, em 5 de fevereiro de 1895, ajuda a perceber os órgãos da Instrução Pública "em funcionamento" (Quadro 2). Vale ressaltar que "nos documentos do período, é comum denominar a Secretaria Geral de Instrução Pública de Diretoria” (PAULO, 2007, p. 57). 
Quadro 2 - Ofício do diretor geral em 1895.

\section{DIRECTORIA DA INSTRUÇÃO PÚBLICA DO ESTADO DE SÃO PAULO \\ 5 de fevereiro de 1895}

$1^{\mathrm{a}}$ SECÇÃO - n. 155

Solicito de vossa parte as providencias necessárias para atender a reclamação que me foi feita pelo inspetor do $2^{\mathrm{O}}$ distrito escolar, por parte de D. Isabel de Serpa e Souza, professora da escola do $11^{\circ}$ distrito desta capital, no sentido de serem fornecidos para uso dela, os livros e objetos constantes na relação junta.

Acredito que, dentre eles, alguns possa fornecer o almoxarifado que por falta de espaço em seus aposentes ainda não pode definir o conteúdo de 16 caixões remetidos da Escola Normal e em seu depósito.

Ao ilustre cidadão Dr. Cesário Motta Junior M.D. Secretário de Estado dos Negócios do Interior O Diretor Geral - Arthur Guimarães

Fonte: Apesp - Instrução Pública - Ofícios do Governo ao Inspetor Geral. Anos = 1894-1896. Ordem 4492.

Trata-se de um ofício do Diretor Geral da Instrução Pública, Arthur Cesar Guimarães, ao Secretário de Estado dos Negócios do Interior, Cesário Motta Junior. É um ofício de 5 de fevereiro, portanto, anterior à organização do almoxarifado, o que é atestado pelo último parágrafo. O almoxarifado da Secretaria do Interior não tinha "espaço em seus aposentos" e, por isso, o material da instrução pública passava, ainda, por uma guarda temporária no depósito da Escola Normal da Praça da República.

O assunto do ofício interessa à $1^{\mathrm{a}}$ seção, ou seja, às escolas preliminares e complementares, conforme Decreto n. 144A, de 30 de dezembro de 1892 e Lei n. 88 , de 8 de setembro de 1892. A hierarquia é outro aspecto que chama a atenção. Interessa saber como os móveis e objetos chegariam aos estabelecimentos de ensino a partir desta estrutura hierárquica.

Uma professora primária passa ao inspetor do distrito uma relação de objetos necessários ao uso da escola. Este transmite o pedido ao Diretor Geral da Instrução Pública que, por sua vez, solicita as providências para satisfação do 
pedido ao Secretário de Estado dos Negócios do Interior. O objeto da solicitação encontraria solução não mais no presidente do Estado, mas em funcionário a ele subordinado, o Secretário do Interior. Entretanto, quando a morosidade do serviço público exacerbava, reaparecia a "tentação" de recorrer aos antigos métodos. É o que indicia o ofício a seguir, no Quadro 3.

Quadro 3 - Ofício do Inspetor do Distrito em 1895.

\section{INSPECTORIA DO $2^{\circ}$ DISTRICTO LITTERÁRIO}

em S. Carlos de Pinhal, 30 de agosto de 1895

Oficio n. 391

$3^{\text {a }}$ Secção - Chefe

14-9-1895

Accusando o recebimento dos vossos officios sob n. 960 e 1001 cumpre-me declarar-vos que quanto a primeira parte do primeiro em data de 22 de junho vos enviei o oficio de n. 346 acompanhado dos mappas e relatórios das escolas do districto, os quais me foram devolvidos para dos devidos reparos, ficando na secretaria os respectivos relatórios.

Quanto ao de n. 1001:

Infelizmente as escolas deste districto, salvo uma ou outra que encontrei com alguns moveis estragados ainda não receberam mobilia nem objetos necessários ao ensino moderno não obstante os muitos pedidos que esta inspetoria tem feito diretamente a esta Diretoria.

Podeis ficar certo de que ainda não desviei do caminho legal para fazer qualquer pedido ao Governo em beneficio da instrução do districto.

Saúde e Fraternidade

Ao ilustre cidadão doutor - Arthur Cesar Guimarães Digníssimo Diretor Geral da Instrução Pública de S. Paulo

Fonte: Série Manuscritos. Secretaria do Interior - Escolas Complementares. Maço 317 - caixa $322-$ ordem 6927 , anos = 1897 a 1904.

Se o ofício n. 155 é endereçado pela Diretoria ao Secretário do Interior, o de n. 391, é do Inspetor do Distrito à Diretoria. A expressão do último parágrafo, "desviei do caminho legal", tratava-se de uma ameaça do inspetor, pois diante dos "muitos pedidos" feitos "diretamente a esta Diretoria" e não atendidos, ele "ainda" não havia recorrido ao Governo, ou seja, ao Presidente do Estado. Atropelar a estrutura hierárquica e burocrática, “importunar" o Presidente com um serviço que não era sua função precípua, atestaria a ineficiência dos 
funcionários competentes, o Secretário do Interior e o Diretor Geral.

Há um conjunto de ofícios dos inspetores literários entre agosto e setembro de $1895^{12}$, todos tratando de material e móveis escolares. Provavelmente, tratava-se de uma resposta à consulta feita pelo Diretor Geral da Instrução Pública. O ofício n. 391 é uma resposta a outros ofícios endereçados pelo chefe da $3^{\text {a }}$ seção da Secretaria Geral da Instrução Pública, responsável pelo serviço do Conselho Superior, do ensino privado e da estatística escolar.

Foi, possivelmente, no interesse da estatística escolar que se deu a troca destes ofícios, tanto porque foram endereçados à $3^{\mathrm{a}}$ seção, como por causa dos mapas e relatórios solicitados ao Diretor Geral. Os ofícios indiciam as primeiras tentativas do governo paulista de fazer um levantamento mais sistemático das condições físicas, materiais e mobiliárias das escolas. Não havia um levantamento sistemático de dados para se tomar conhecimento das escolas equipadas ou não com mobiliário. Não era o poder público que ia até a escola. A escola precisava reclamar suas necessidades básicas.

O uso da estatística para administração do ensino público é outro sinal da racionalização e burocratização nos anos iniciais da República. Durante o Império e, ainda, nos anos iniciais da República, não havia uma política pública de distribuição do material e mobiliário escolar. A ausência de órgãos que se responsabilizassem, de forma sistemática, pela aquisição e distribuição dos objetos necessários à escola, tornava moroso e desigual o suprimento material das instituições de ensino.

O regime republicano trouxe mudanças, sobretudo na legislação, mas para além da legislação, há permanências na condução dos negócios públicos. Embora, no plano legal, as reformas da instrução pública nos anos iniciais do regime republicano tornaram mais complexa e burocrática a organização da

\footnotetext{
${ }^{12}$ Serie manuscritos. Secretaria do Interior. Escolas complementares. Maço 317 - caixa 322 Ordem 6927. Anos 1897 a 1904. A documentação da lata é datada de 1897 a 1904, todavia, há documentos anteriores a 1897 , como os ofícios destacados.
} 
administração pública e escolar, por vezes as relações pessoais ainda se sobrepunham à hierarquia.

Vai desaparecendo, já nos primeiros anos republicanos, a prática de entrega de verbas diretamente aos professores para aquisição de móveis. A criação do almoxarifado da instrução pública, em 1895, é um importante passo na modernização do serviço de aquisição, arrecadação e distribuição do material e mobiliário escolar. Entretanto, se algumas dificuldades administrativas persistem na passagem do Império para República, não é diferente no que concerne às questões econômicas, como se verá a seguir.

\section{O DESAFIO DO INVESTIMENTO DO GOVERNO NA INSTRUÇÃO PÚBLICA}

Tratar do investimento do governo na educação pública exige pensar, simultaneamente, a estruturação da máquina administrativa para ampliação do serviço educacional, e a partir dos orçamentos (história econômica), o destino da receita, os gastos com a instrução pública. De acordo com o Ato Adicional de 1834, "a receita e a despesa da Província seria fixada em orçamento apresentado pelo Presidente [da Província], e a dos Municípios em orçamento apresentado pelas respectivas Câmaras, ambos sujeitos à aprovação pela Assembléia Provincial" (TESSITORE, 1995, p. 65).

A análise da série de orçamentos coloca em evidência os gastos do governo com a instrução pública nos últimos anos do Império e nos primeiros anos da República. Para abordar este tema lançarei mão dos orçamentos para a instrução pública e dos Relatórios dos Presidentes da Província do Estado de São Paulo. É preciso ressaltar que os valores estabelecidos nos orçamentos serão considerados mais pelo que podem revelar acerca daquilo que o governo compreendia como suficiente para a instrução pública e menos pela exatidão de tais valores. 
Serão analisados os orçamentos a partir de 1859 (Tabela 1), ano da organização do Tesouro Provincial e, portanto, da "separação definitiva entre as Tesourarias geral e provincial [...]” (TESSITORE, 1995, p. 86). A Contadoria Provincial foi transformada em Thesouro Provincial e "passava a integrar um órgão propriamente provincial, independente da Repartição geral, com estrutura e funcionários próprios” (TESSITORE, 1995, p. 86).

Tabela 1 - Orçamentos para Instrução Pública.

\begin{tabular}{|c|c|c|}
\hline ANO & MÓVEIS E UTENSIS & INSTRUÇÃO PÚBLICA \\
\hline $\begin{array}{l}10^{\circ} \text { de Julho de } 1859 \text { a } \\
30 \text { de Junho de } 1860\end{array}$ & Não consta & $112.394 \$$ оOо \\
\hline $\begin{array}{l}\text { 1. }^{\circ} \text { de Julho de } 1861 \text { a } \\
\text { 30 de Junho de } 1862\end{array}$ & $2.000 \$ 000$ & $110.997 \$ 010$ \\
\hline $\begin{array}{l}\text { 1. }^{\circ} \text { de Julho de } 1862 \text { a } \\
\text { 30 de Junho de } 1863\end{array}$ & Não consta & $155.000 \$ 000$ \\
\hline $\begin{array}{l}\text { 1. }^{\circ} \text { de Julho de } 1863 \text { a } \\
\text { 30 de Junho de } 1864\end{array}$ & $2.000 \$ 000$ & $169.921 \$ 030$ \\
\hline $\begin{array}{l}\text { 1. }^{\circ} \text { de Julho de } 1864 \text { a } \\
\text { 30 de Junho de } 1865\end{array}$ & $2.000 \$ 000$ & $199.000 \$ 000$ \\
\hline $\begin{array}{l}\text { 1. }^{\circ} \text { de Julho de } 1865 \text { a } \\
\text { 30 de Junho de } 1866\end{array}$ & $2.000 \$ 000$ & $172.573 \$ 330$ \\
\hline $\begin{array}{l}\text { 1. }^{\circ} \text { de Julho de } 1866 \text { a } \\
\text { 30 de Junho de } 1867\end{array}$ & $2.000 \$ 000$ & $155.634 \$$ ооо \\
\hline $\begin{array}{l}\text { 1. }^{\circ} \text { de Julho de } 1867 \text { a } \\
\text { 30 de Junho de } 1868\end{array}$ & $2.000 \$ 000$ & $146.924 \$ 000$ \\
\hline $\begin{array}{l}\text { 1. }^{\circ} \text { de Julho de } 1868 \text { a } \\
\text { 30 de Junho de } 1869\end{array}$ & $2.000 \$ 000$ & $166.645 \$ 000$ \\
\hline $\begin{array}{l}\text { 1. }^{\circ} \text { de Julho de } 1869 \text { a } \\
30 \text { de Junho de } 1870\end{array}$ & $2.000 \$ 000$ & $191.984 \$$ оOо \\
\hline $\begin{array}{l}\text { 1. }^{\circ} \text { de Julho de } 1870 \text { a } \\
\text { 30 do Junho de } 1871\end{array}$ & 4:000\$000 & $258: 082 \$ 660$ \\
\hline $\begin{array}{l}1^{\circ} \text { de Julho de } 1871 \text { a } \\
30 \text { de Junho de } 1872\end{array}$ & 4:000\$000 & $272: 438 \$ 660$ \\
\hline $\begin{array}{l}1^{\circ} \text { de Julho de } 1872 \text { a } \\
30 \text { de Junho de } 1873\end{array}$ & $4: 000 \$ 0^{13}$ & $345: 612 \$ 660$ \\
\hline
\end{tabular}

${ }_{13}$ Primeira vez que aparece "móveis e utensílios" no orçamento provincial. 


\begin{tabular}{|c|c|c|}
\hline ANO & MÓVEIS E UTENSIS & INSTRUÇÃO PÚBLICA \\
\hline $\begin{array}{l}1^{\circ} \text { de Julho de } 1873 \text { a } \\
30 \text { de Junho de } 1874\end{array}$ & 4:000\$000 & 380:199\$330 \\
\hline $\begin{array}{l}1^{\circ} \text { de Julho de } 1874 \text { a } \\
30 \text { de Junho de } 1875\end{array}$ & 4:000\$000 & $397: 979 \$ 330$ \\
\hline $\begin{array}{l}1^{\circ} \text { de Julho de } 1875 \text { a } \\
30 \text { de Junho de } 1876\end{array}$ & 4:000\$000 & $404: 355 \$ 990$ \\
\hline $\begin{array}{l}1^{\circ} \text { de Julho de } 1876 \text { a } \\
30 \text { do Junho de } 1877\end{array}$ & 4:000\$000 & Não informado \\
\hline $\begin{array}{l}1^{\circ} \text { de Julho de } 1877 \text { a } \\
30 \text { de Junho de } 1878\end{array}$ & 4:000\$000 & Não informado \\
\hline $\begin{array}{l}1^{\circ} \text { de Julho de } 1880 \text { a } \\
30 \text { de Junho de } 1881\end{array}$ & 5:000\$000 & $532: 816 \$ 580$ \\
\hline $\begin{array}{l}\text { 1. }{ }^{\circ} \text { de Julho de } 1882 \text { a } \\
\text { 30 de Junho de } 1883\end{array}$ & $\begin{array}{l}\text { 25:000 } \$ 000 \text { (Moveis, utensis e } \\
\text { aparelhos necessarios para o ensino de } \\
\text { chimica e physica na Escóla Normal) }\end{array}$ & $500: 460 \$ 000$ \\
\hline $\begin{array}{l}1^{\circ} \text { de Julho de } 1883 \text { a } \\
30 \text { de Junho de } 1884\end{array}$ & $\begin{array}{l}\text { 20:000 } \$ 000 \text { (Moveis, utensilios e } \\
\text { livros para as escholas) }\end{array}$ & $455: 640 \$ 000$ \\
\hline $\begin{array}{l}1^{\circ} \text { de Julho de } 1884 \text { a } \\
30 \text { de Junho de } 1885\end{array}$ & $\begin{array}{l}\text { 20:000 } \$ 000 \text { (Moveis, utensis e livros } \\
\text { para as escholas públicas) }\end{array}$ & 600:000\$000 \\
\hline
\end{tabular}

\begin{tabular}{|c|c|c|}
\hline ANO & MÓVEIS E UTENSIS & INSTRUÇÃO PÚBLICA \\
\hline $\begin{array}{l}\text { 1. }{ }^{\circ} \text { de Julho de } 1885 \text { a } \\
30 \text { de Junho de } 1886\end{array}$ & $\begin{array}{l}\text { 20:00o } \$ \text { ooo (Moveis, utensis e livros } \\
\text { para as escholas) }\end{array}$ & $605: 830 \$ 000$ \\
\hline $\begin{array}{l}1^{\circ} \text { de Julho de } 1886 \text { a } \\
30 \text { de Junho de } 1887\end{array}$ & $\begin{array}{l}\text { 20:000 } \$ \text { ooo (Moveis, utensis e livros } \\
\text { para as escholas) }\end{array}$ & $830: 490 \$ 040$ \\
\hline $\begin{array}{l}1^{\circ} \text { de Julho de } 1887 \text { a } \\
30 \text { de Junho de } 1888\end{array}$ & $\begin{array}{l}\text { 10:00o } \$ 000 \text { (Moveis, utensis e livros } \\
\text { para as escholas) }\end{array}$ & 780:000\$000 \\
\hline $\begin{array}{l}1 \text { de Julho de } 1888 \text { a } \\
30 \text { de Junho de } 1889\end{array}$ & Não orçado & $918: 420 \$ 000$ \\
\hline $\begin{array}{l}1 \text { de Julho de } 1889 \text { a } \\
30 \text { de Junho de } 1890\end{array}$ & $\begin{array}{l}\text { 3:ooo } \$ \text { ooo (Compra de livros e } \\
\text { objectos necessarios ás aulas) }\end{array}$ & $918: 420 \$ 000$ \\
\hline $\begin{array}{l}\text { 1. }{ }^{\circ} \text { de Julho de } 1890 \text { a } \\
\text { 30 de Junho de } 1891\end{array}$ & $\begin{array}{l}\text { 6:00o } \$ \text { ooo (Mobilia, livros e objectos } \\
\text { manuaes ás aulas) }\end{array}$ & $1.343: 844 \$ 800$ \\
\hline $\begin{array}{l}\text { 1. }{ }^{\circ} \text { de Janeiro a } 31 \text { de } \\
\text { Dezembro de } 1892\end{array}$ & Não orçado & $2.265: 680 \$ 000$ \\
\hline $\begin{array}{l}\text { 1. }{ }^{\circ} \text { de Janeiro a } 31 \text { de } \\
\text { Dezembro de } 1893\end{array}$ & Não orçado & $3.924: 340 \$ 000$ \\
\hline
\end{tabular}




\begin{tabular}{|c|c|c|}
\hline ANO & MÓVEIS E UTENSIS & INSTRUÇÃO PÚBLICA \\
\hline $\begin{array}{l}1 .^{\circ} \text { de Janeiro a } 31 \text { de } \\
\text { Dezembro de } 1894^{14}\end{array}$ & $\begin{array}{l}\text { 77:400 } \$ \text { ooo (Expediente, compra de } \\
\text { móveis, aluguel de prédios e outras } \\
\text { despesas). }\end{array}$ & $3.815: 300 \$ 000$ \\
\hline $\begin{array}{l}\text { 1. }{ }^{\circ} \text { do Janeiro a } 31 \text { de } \\
\text { Dezembro de } 1895\end{array}$ & $\begin{array}{l}\text { 10:00o\$ooo (Expediente e outras } \\
\text { despesas da E. Normal) + } \\
\text { 150:000 } \$ \text { ooo (Material escolar das } \\
\text { escolas públicas) }\end{array}$ & $4.823: 480 \$ 000$ \\
\hline $\begin{array}{l}\text { 1. }{ }^{\circ} \text { de Janeiro a } 31 \text { de } \\
\text { Dezembro de } 1896\end{array}$ & $\begin{array}{l}\text { 20:000 } \$ \text { ooo (Expediente e outras } \\
\text { despesas da E. Normal) + } \\
\text { 200:000 } \$ \text { Ooo (Material escolar e } \\
\text { livros das escolas públicas) }\end{array}$ & $5 \cdot 390: 880 \$ 000$ \\
\hline $\begin{array}{l}1 .^{\circ} \text { de Janeiro a } 31 \text { de } \\
\text { Dezembro de } 1897\end{array}$ & $\begin{array}{l}\text { 15:00o\$00o (Expediente e outras } \\
\text { despesas da E. Normal) + } \\
\text { 200:00o } \$ \text { ooo (Material escolar e } \\
\text { livros das escolas públicas) }\end{array}$ & $\begin{array}{l}6.599: 820 \$ 000 \\
1^{\text {a }} \text { vez que tem } \\
\text { especificação de despesas } \\
\text { para grupos escolares (25). }\end{array}$ \\
\hline
\end{tabular}

Fonte: Elaboração da autora a partir das leis orçamentárias da Província e do Estado de São Paulo, de 1859 a 1897.

Comparando os orçamentos deste período com os registros do já citado Livro de Moveis e Utensis (Distribuição de 1854 a 1872), conclui-se que o valor não correspondia ao mínimo suficiente, ainda mais quando se considera que os 2:000 \$ooo seria para compra, não só dos móveis, mas de todos os utensílios da escola.

No ano de 1870, o Livro registra somente onze escolas foram providas com móveis, totalizando um gasto de 921\$ooo. Nesse ano, o Relatório do Inspetor Geral da Instrução Pública, de 1871, informa que "entre publicas e particulares contamos com pouco mais de 400 escolas para população calculada em 800.000 almas"15. Observa-se uma notável disparidade entre o número de escolas e o número de crianças em idade escolar a serem atendidas.

A Lei n. 54 de 15 de abril de 1868, no artigo 22, autorizava o Presidente

\footnotetext{
${ }^{14}$ Neste ano há a criação de diversas escolas e cadeiras de primeiras letras.

${ }^{15}$ Secretaria da Inspetoria Geral da Instrução Pública. Relatório apresentado pelo Inspetor Geral da Instrução Pública, Diogo de Mendonça, em 31 de dezembro de 1870, anexo ao Relatorio apresentado á Assembléa Legislativa Provincial de S. Paulo pelo Presidente da Provincia, o Exm. Sr. Dr. Antonio da Costa Pinto Silva, no dia 5 de fevereiro de 1871. S. Paulo, Typ. Americana, 1871, p. 6.
} 
da Província a "dispender, desde já, até a quantia de seis contos de réis com a compra de livros, moveis e utensílios para as escholas publicas”. No entanto, a primeira destinação de verba para aquisição de móveis ocorre no exercício financeiro de 1872 a 1873. Ainda assim, não foram orçados seis, mas quatro contos de reis. Esse valor permaneceu inalterado até o ano de 1878, indicando que a criação das cadeiras de primeiras letras e escolas não foi acompanhada de uma ampliação na verba destinada a equipá-las.

Por um lado, a existência de lei estipulando uma quantia para aquisição de móveis e utensis não era garantia de que seria estabelecida, nas leis orçamentárias, a verba devida para aquele fim. Por outro lado, a ausência da lei não significa que não foram adquiridos móveis e utensis para as escolas públicas antes da lei orçamentária de 1872, ou, antes da lei n. 54 de 1868. No Livro de Móveis e Utensis, por exemplo, há registro de compra de móveis desde o ano de 1854 .

De todo modo, o valor da verba para compra de móveis permaneceria inalterado por anos seguidos. Exceção a essa situação ocorre no exercício financeiro de 1882 a 1883 . É notável a elevação da verba destinada a melhora das condições da escola, passando de 5:000\$0oo para 25:000\$00o. Contudo, esse valor beneficiaria uma única escola - a Escola Normal de São Paulo. Não é desprezível a menção de que o valor seria empregado, também, para compra de "aparelhos necessarios para o ensino de chimica e physica na Escóla Normal", diferenciando estes materiais dos demais utensis. Todavia, o investimento no ensino de ciências naturais, no final do século XIX, será uma discussão posterior.

No exercício financeiro seguinte (de 1883 a 1884), estipula-se 20:000\$000, desta vez, destinados à aquisição de móveis, utensílios e livros para as escolas públicas e não apenas para a Escola Normal. A Escola Normal possuía uma verba de expediente, separada da verba das demais escolas públicas, para aquisição de móveis e material escolar. Em alguns orçamentos, somente aquela instituição era agraciada com a dotação orçamentária para este 
fim.

O maior valor orçado para aquisição de mobiliário escolar, no período estudado, foi de $20.000 \$ 000$, nos anos de 1883 e 1884 . De acordo com o Relatório sobre o estado e necessidade da Instrucção Publica da Província de S. Paulo, do ano de 1884, foram 35 escolas providas com móveis e utensis, pela verba do exercício de 1883 a $1884^{16}$. Diante da quantidade de solicitações, houve critérios para estabelecer a prioridade no atendimento às escolas. Foram "attendidas de preferência as reclamações a favor daquellas escholas que mais o mereciam por sua importância, determinada, pela quantidade de alumnos, e já pelo aproveitamento do ensino" 17 .

Em 1885, outras 20 escolas foram autorizadas a comprar móveis e utensis. Na compra dos materiais "necessários ás suas escholas", os professores deveriam guardar "as regras observadas a respeito daquelles fornecimentos". As regras, provavelmente, diziam respeito a tabelas "pelas quaes deviam ser feitos os fornecimentos de materiaes ás escholas publicas".

Isso ajuda a entender porque, no Livro de Moveis e Utensis, a tabela para a quantidade e valor das mesas e dos bancos é pouco variável. Embora os registros do Livro se estendam somente até o ano de 1872, ele indicia a existência de uma tabela, um valor mais ou menos fixo, para compra de móveis pelos professores. Para a maior parte dos professores e das professoras é liberada, pelo Thesouro Provincial, a verba de 80\$0oo. Esse valor seria suficiente para compra de:

- 6 bancos de 10 palmos de comprimento $=27 \$ 000$

- 3 bancos de 10 palmos de comprimento e $2 \frac{1}{1 / 2}$ de largura $=15 \$ 000$

- 1 meza de 5 palmas em quadro $=20 \$ 000$

- 1 cadeira para o professor $=18 \$ 000$

${ }^{16}$ SÃO PAULO. Relatório sobre o estado e necessidades da Instrucção Publica da Província de S. Paulo, do ano de 1884 apresentado ao Exm. Snr. Presidente da Província no ano de 1884, pelo Inspetor Geral. São Paulo, Typ. King a Vapor, 1885, p. 71.

17 Idem, p. 13. 
Além do controle fixado na tabela, há uma coerção sobre os professores a fim de evitar o desvio do patrimônio público. A medida consistia em condicionar a remoção dos professores públicos primários à comprovação da entrega dos materiais das escolas, por eles adquiridos. Assim, "as remoções, permutas de cadeiras e demissões não sejam concedidas aos Professorespublicos-primarios, sem que pelos Inspetores Literários de districtos, ou os Presidentes das respectivas Câmaras Municipaes, tenha sido informado que, por inventário, fizeram elles entrega dos materiaes das respectivas escholas"18.

Se a definição de um controle sobre os móveis comprados pelos professores tornou-se uma necessidade é porque isso se constituiu um problema a ser sanado. No Livro de Moveis e Utensis consta um registro, feito em 1870, de uma expedição de ordem no valor de 80\$000 para pagamento dos móveis comprados pela professora da Cadeira de Primeiras Letras do sexo feminino de Brotas, D. Thereza de Arruda Ferraz. Três anos depois, é feita uma retificação neste registro, pois "em ofício de 16 de abril de 1873, o Inspetor do Thesouro declarou não ter sido efetuada a compra destes móveis"19. No caso, não é possível assegurar o motivo da correção do Livro. Contudo, é possível que, três anos após a suposta compra, a professora deixou a escola e não prestou conta dos móveis.

A Lei n. 6, de 13 de março de 1878 , no seu artigo $1^{\circ}$, determinou que nenhuma despesa, ainda que autorizada por lei especial, ou ordenada pelo presidente da Província, poderia ser feita pelo Tesouro Provincial, sem que se achasse consignada no respectivo crédito da Lei do Orçamento.

Do início ao fim da década de 1880 a verba destinada a Instrução Pública chega a quase dobrar. De 1882 a 1883 é orçado 500:460\$0oo. De 1888 a 1889, o valor chega a 918:420\$ooo. Mais significativa é a verba orçada para

\footnotetext{
${ }^{18}$ SÃO PAULO. Relatório sobre o estado e necessidades da Instrucção Publica da Província de S. Paulo, do ano de 1884 apresentado ao Exm. Snr. Presidente da Província no ano de 1884, pelo Inspetor Geral. São Paulo, Typ King a Vapor, 1885, p. 14.

${ }^{19}$ Arquivo Público do Estado de São Paulo. Secretária da Instrução Pública de São Paulo. Ordem 1124 - Livro de Móveis e Utensis (Distribuição de 1854 a 1872), p. 77, verso.
} 
móveis e utensis. De 5:000\$ooo, estipulado no início da década de 1880, esse valor sobe para 25:000\$000 e se mantém em 20:000\$000 até quase o fim da década, quando cai novamente para 10:000\$ooo.

Outro elemento que corrobora com a ideia de que nos últimos anos do regime monárquico houve uma tentativa de incremento do investimento das condições físicas da escola pública é o Fundo Escolar, criado pela Lei ${ }^{\circ}$ 81, de 06/04/1887, que reforma a instrução pública. O Fundo Escolar é, talvez, a primeira experiência de vinculação de recursos para educação.

De acordo com Romualdo Portela Oliveira, a vinculação é "a previsão, no texto, constitucional, de uma alíquota mínima da receita de impostos a ser aplicada em educação" (OLIVEIRA, 2001, p. 96). Ela ocorre pela primeira vez, "em nível nacional na Constituição de 1934" (OLIVEIRA, 2001, p. 97). No caso de São Paulo, o Fundo Escolar de 1887 pode ser tomado como uma primeira tentativa de elevação do montante aplicado em educação, por meio dos recursos provenientes das seguintes fontes:

Donativos e legados para a instruç̧ão publica. Producto das multas creadas por esta lei. Producto das multas que por lei não tem destino especial. Producto do imposto de capitação creado por esta lei, e pelas dotações feitas nos orçamentos provincial e municipal ${ }^{20}$.

Em 21 de fevereiro de 1888, o Conselho Municipal de Santa Cruz das Palmeiras, consulta o Diretor Geral da Instrução Pública para saber "se as despezas com a restauração e o fornecimento da mobília das escolas deveriam ser custeadas pelo fundo ultimamente creado em favor da instrucção provincial e quaes as providências a adoptar, desde que a elle não se pudesse recorrer" ${ }^{21}$.

O diretor da Instrução Pública, Francisco de Paula Rodrigues Alves, respondeu de acordo com o ofício recebido do presidente da Província, que "ao

\footnotetext{
${ }^{20}$ São Paulo. Lei n ${ }^{\circ}$ 81, de 06/04/1887, Art.91, incisos 1, 2, 3, 4.

${ }^{21}$ Decisões da Presidência, anexo ao Relatorio apresentado á Assembléa Legislativa Provincial de São Paulo pelo presidente da provincia, dr. Pedro Vicente de Azevedo, no dia 11 de janeiro de 1889. São Paulo, Typ. a Vapor de Jorge Seckler \& Comp., 1889. p. 1.
} 
poder legislativo cumpria deliberar a respeito da breve constituição do fundo escolar, por onde tem de correr as despesas alludidas" 22 .

Essa troca de ofícios ratifica o que expõe Viviane Tessitore (1995, p. 181) acerca do Imposto de Capitação para o Fundo Escolar: "As expectativas em torno das reformas de 1887 , porém, foram rapidamente frustadas com relação às metas do Fundo Escolar". O objetivo do Fundo era a "construcção de casas, acquisição de moveis, utensis e outros objectos de que precisarem as escolas do mesmo municipio" 23 .

Essa "forma de financiamento" da educação foi atribuída aos municípios, pois o Fundo não era provincial, mas "creado em cada município" e a aplicação das quantias arrecadadas estava na competência e discricionariedade dos Conselhos Municipais24. Porém, "os Conselhos Municipais, que deveriam aplicar sua receita, de acordo com o Presidente Rodrigues Alves, não eram criados, quando criados, não se instalavam, e, quando instalados, não tinham estabilidade e cumpriam deficientemente suas funções” (TESSITORE, 1995, p. 181).

Nos primeiros anos republicanos, pelo menos nos orçamentos, os valores estipulados para a instrução pública foram decrescentes em relação ao império. De 1889 a 1890 houve uma drástica redução da verba de 20:000\$000 para 3:000\$0oo, somente para os objetos da escola, não aparecendo a expressão "móveis". No exercício seguinte, de 1890 a 1891, é orçado 6:000\$000 para objetos e mobília. Por dois anos seguidos, 1892 e 1893 não foi orçada nenhuma verba, seja para utensílios, seja para móveis. Já em 1894, estipula-se o valor de 77:400\$500 para aquisição de móveis e utensis para as escolas públicas paulista. É a última menção de valor orçado de móveis e objetos para todas as escolas públicas, pois na primeira década republicana, os valores estipulados, entre 10:000\$000 e 20:000\$000, para expediente, móveis e utensílios é

\footnotetext{
22 Idem, p. 2.

${ }^{23}$ São Paulo. Lei no 81, de 06/04/1887, Art. 91.

24 Idem, art. 91, 95 e 97.
} 
destinado apenas para a Escola Normal de São Paulo.

Isso não significa que, nenhuma outra escola pública paulista recebeu material ou mobiliário. Mas, pode sinalizar a concentração dos esforços dos republicanos na visibilidade das escolas modelos, sobretudo, na Escola Normal da Praça da República. A leitura e comparação das leis orçamentárias permite cotejar a hipótese de que, na década de 1880, a verba orçada para móveis e utensis seria destinada às escolas públicas espalhadas pelo território paulista. Enquanto a verba de expediente, entre 1895 e 1898, teve destinação específica para a Escola Normal.

Isso pode ajudar a entender porque a escola da Praça da República e as escolas modelos eram equipadas com os mais modernos materiais e mobiliário escolar, eram as destinatárias dos objetos importados (ALCÂNTARA, 2014), enquanto as demais instituições de ensino espalhados pelo território padeciam por falta de móveis e objetos básicos ao seu funcionamento.

É preciso revisitar a documentação que trata das questões econômicas da escola para interrogar se a profusão material da Escola Normal de São Paulo e a visibilidade do investimento do governo republicano, nesta instituição, não tornaram invisíveis e pouco problemáticas as condições físicas, de criação e funcionamento, de grande parte das escolas públicas de primeiras letras, nas quais se deu a escolarização da maior parte do povo paulista, no período.

\section{CONSIDERAÇÕES FINAIS}

Tomar a materialidade da escola como fio condutor da análise ajudou a problematizar o investimento do Estado na educação, no processo de criação e expansão da escola moderna, pública, obrigatória e de massa.

Para fazer a distribuição de material e mobiliário para as escolas espalhadas pelo território paulista, o governo precisou se organizar administrativa e economicamente. A estrutura burocrático-administrativa pode 
se constituir em um entrave ou elemento facilitador para o conhecimento e suprimento das necessidades materiais das escolas. Nesta pesquisa, buscou-se apontar indícios de como São Paulo foi se organizando para atender a escolaridade obrigatória. O que coloca em evidência a distância entre a lei (a lei orçamentária, por exemplo) a e a sua efetivação pelo poder público (o gasto com educação). Embora não haja novidade nesta conclusão, demonstrar essa distância no caso concreto, pode ajudar a compreender os desafios locais e regionais que precisam ser enfrentados, ainda hoje.

O investimento do Estado na educação pública e o financiamento da educação é, até os dias atuais, um desafio para o poder público. Ele está colocado na "tensão entre o centro político e a ordem econômico-social" (COSTA, 2000, p. 52). O governo decide o modo como se dará o investimento, se serão criados impostos específicos para financiar a instrução pública, se uma parcela da arrecadação total será a esse fim destinada. De qualquer modo, a fiscalidade, chamada por Wilma Peres Costa de "alma do Estado", tem estreita relação não só com a construção do Estado moderno, mas com os serviços públicos por ele prestados.

Não quero com isso afirmar que a cobrança de mais impostos é sinônimo de eficiência da pulsão extrativa (COSTA, 2000) do Estado que, por sua vez, garantiria maior investimento na educação. Pelo contrário, a breve problematização, aqui, dos orçamentos, das finanças públicas e do investimento na educação tem a ver com um alerta feito por Costa (2000) no sentido de analisar as finanças públicas "em sua relação com as articulações de interesses que permeiam a vida social e a ação politica” (COSTA, 2000, p. 65). Isso corrobora para um tratamento menos técnico e mais politizado das questões entre econômica e educação; entre opções políticas e serviços públicos; entre Estado e investimento na instrução das massas. Daí a importância de se fazer uma História Econômica da escola, perpassada, todavia, por uma história política-administrativa e cultural. 


\section{REFERÊNCIAS}

ALCÂNTARA, Wiara Rosa Rios. Por uma história econômica da escola: a carteira escolar como vetor de relações (São Paulo, 1874-1914). 2014. 339 f. (Doutorado em Educação) - Faculdade de Educação, Universidade de São Paulo, São Paulo, 2014.

CANDEIAS, Antonio (Org). Alfabetização e Escola em Portugal nos séculos XIX e XX: os censos e as estatísticas. Lisboa: Gulbenkian, 2004.

COSTA, Wilma Peres. Finanças e construção do Estado: fontes para o estudo da história tributária do Brasil no século XIX. America Latina en la historia económica, Ciudad de Mexico, v. 15, n. 13/14, p. 51-67, 2000.

OLIVEIRA, Romualdo Portela de; ADRIÃO, Theresa (Org.). Gestão, financiamento e direito à educação: análise da LDB e da Constituição Federal. São Paulo: Xamã, 2001.

PAULO, Marco Antônio Rodrigues. A organização administrativoburocrática da instrução pública paulista: Estudo sobre o Regulamento da Diretoria Geral de 1910. 2007. Tese (Doutorado) - Faculdade de Educação, Universidade de São Paulo, São Paulo, 2007.

REIS FILHO, Casimiro dos. A educação e a ilusão liberal. São Paulo: Cortez Autores.

TESSITORE, Viviane. Fontes da riqueza pública: tributos e administração tributária na província de São Paulo (1832-1892). 1995. Dissertação (Mestrado) - Universidade de São Paulo/USP, São Paulo, 1995.

VIDAL, Diana Gonçalves. Faces da obrigatoriedade escolar: lições do passado, desafios do presente. In: VIDAL, Diana; SÁ, Elizabeth; SILVA, Vera Gaspar da. (Org.). Obrigatoriedade escolar no Brasil. Cuiabá: EdUFMT, 2013, v. 1, p. 11-20. 
professora titular de Ensino Fundamental I na Prefeitura Municipal de São Paulo. Atualmente, é professora da Universidade Federal de São Paulo Unifesp/Diadema. Atua principalmente nos seguintes temas: Formação de professores; Memória e profissão docente; Cultura Escolar; Cultura Material Escolar; História Econômica da Escola; Legislação escolar; História da Administração escolar. Membro do Grupo de Pesquisa em História da Educação em Ciências (Unifesp/Diadema) e do Núcleo Interdisciplinar de Estudos e Pesquisas em História da Educação (Niephe-USP).

E-mail: wiaraped@yahoo.com.br

(i) http://orcid.org/0000-0003-0752-8257

Recebido em: 07 de abril de 2018

Aprovado em: 06 de maio de 2019

Revista História da Educação - RHE

Associação Sul-Rio-Grandense de Pesquisadores em História da Educação - Asphe Artigo de acesso aberto distribuído nos termos de licença Creative Commons. 